\title{
Analysis and Translation Strategies of Public Signs from the Perspective of Pragmatics
}

\author{
Xuqing Shi \\ Qinghai Nationalities University, Xining 810000, Qinghai, China
}

Abstract: With the improvement of China's internationalization level, public signs in Chinese and English can be used universally. But in such cross-cultural communication, cultural differences in different countries inevitably lead to misunderstanding and even cultural conflict. Pragmatic failure is a common problem in cross cultural communication of public signs, because different languages carry different pragmatic rules and pragmatic constraints. This paper, under the framework of pragmatics, uses pragmatic failure theory to analyze pragmatic failure in the translation of public signs and put forward corresponding translation strategies in order to promote the harmony of the expression of mother tongue and target language in intercultural communication, to avoid communication conflicts and to improve the comfort of the language environment of public signs.

Keywords: Public Signs; Pragmatic Analysis; Translation Strategies

\section{Introduction}

At present, although the government departments have made corresponding norms to the English translation of public signs, but translation errors still occur frequently in the actual translation process, which not only seriously affects the international image of our country, but also affects the foreign economic and cultural exchanges. At present, the translation of public signs is very mixed. Spelling mistakes, words fail to convey meaning and Chinglish are very common ${ }^{[1]}$. Although many experts do their best to investigate, classify and correct errors, they play an active role in improving the level of regional public signs and provide a reference for the translators to a certain extent, but they seldom stand at the height of the theory, they do not fundamentally solve the problems in the public signs translation.

Pragmatics is a branch of linguistics which studies the ways in which context contributes to meaning. Pragmatics encompasses speech act theory, conversational implicature, talk in interaction and other approaches to language behavior in philosophy, sociology, and linguistics. Pragmatics is a study of the use and understanding of language ${ }^{[2]}$. It not only studies the process of expressing the meaning of the speaker in language and external context, but also studies the decoding and reasoning process of the utterance spoken by the speaker. Pragmatics, like semantics, also studies meaning, but it does not study the meaning of the abstract language system itself, but the meaning of communication and understanding in a specific communicative situation, as well as the process of understanding and communicating. Translation studies are all about the translator's understanding of the original text and the reconstruction of the original meaning in the target text. They have common research objects, namely language understanding and language expression.

Public signs are of great significance in the public and tourist life. Any ambiguity, misunderstanding and abuse of public signs can lead to adverse consequences. Public signs are a medium of information exchange for the public, and are also simple and intuitive external communication images ${ }^{[6]}$. However, there are still many problems exist in public signs translation in many cities, which have misunderstood foreigners and have done great damage to the multi-culture exchanges and foreign language environment, and have influenced the urban culture construction and the environment comfort to some extent. The translation of public signs with good acceptability and good publicity can provide convenience for foreign friends, while the wrong or irregular translations will cause problems for their trips, and even seriously affect the overall image and spirit of a region and even the whole country. This paper will propose a humble opinion to promote the standardization of the translation of public signs. Through consulting a lot of data, I find that pragmatic failure is the most important problem for translators to translate public signs.

\section{The categories and the linguistic cultural characteristics of the public signs}

\subsection{The types of public signs}

Public signs refer to the text displayed in public places, which has the function of providing information and completing

This is an open-access article distributed under the terms of the Creative Commons Attribution Non-Commercial License

(http://creativecommons.org/licenses/by-nc/4.0/), which permits unrestricted non-commercial use, distribution, and reproduction in any medium, provided the original work is properly cited. 
instructions. So the public signs are also called signs, slogans, markings, warning languages and so on ${ }^{[9]}$. According to the summarize of Yang Yonghe (2009) on the Translation of Public Signs, the public signs have now basically replaced other synonyms and become the most commonly used terms from the retrieval of the three Chinese translation academic periodicals. There are many different definitions of public signs. In spite of the wide scope and variety of the public signs, we can divide the public signs into four categories according to their demonstrative functions: indicative public signs, prompting public signs, restrictive public signs and mandatory public signs. 1) Indicative public signs provide information for the masses, without restricting or forcing the public to take some action or execute a command. Therefore, the indicative public signs are mostly composed of noun or noun phrases. For instance, Information Desk 咨询台. 2) Prompting public signs use a mild tone to remind the public that it is intended to facilitate the public or make the public feel the humanistic care, with no restrictions and no mandatory intentions. The purpose of prompting public signs is to remind the public to pay attention to the content, but it does not require the public to take actions, but it is widely used. For example, Wet Floor 小心地滑. 3) Restrictive public signs refer to the restrictions and constrain imposed on the public's behavior by comparing euphemistic tone. Although its language application is straightforward, but because of its relative euphemism, it will not make the public feel tough, rude and unreasonable. Such as, Emergency Use Only 仅限紧急情况下使用. 4)Mandatory public signs, as the name implies, have mandatory requirements for public behavior, require the relevant public not to take or take some kind of action in a straightforward, tough, and unnegotiable manner. The mandatory public signs are strongly tone of voice. It is the most forceful in all the public signs, which requires the audience to be carried out. There is no room for negotiation and It has a strong warning effect. For example, Do Not Speak To The Driver 请勿与驾驶员攀谈.

\subsection{The linguistic and cultural characteristics of the public signs}

Public signs are widely used in terms of nouns, verbs, gerund, phrases, abbreviations, combination of words and symbols, present tense, imperative sentence, standard vocabulary, concise language, and some native vocabulary ${ }^{[7]}$. The language of the public signs is concise and precise, the content is straightforward and the purpose is clear. 1)The wide use of nouns: when there are public signs with "Static" meaning, service, instruction, explanation nature. There are a great deal of nouns. Usually, those signs can show specific information in a direct, accurate and unmistakable way .For example, Food \& Beverage 餐饮部, Business Center 商务中心. 2) The use of verbs: the restrictive, mandatory, and "dynamic" public signs usually consist of amount of verbs and Gerund to make the public's attention focus on the actions required by the public signs producers. Such as, Slow Down 减速 行驶. 3) The use of phrases: verb phrases and noun phrases are widely applied to public signs. These word groups and phrases are simple in structure and diverse in composition. For example, Open Now 营业. 4) The use of abbreviations: public signs of public facilities and services which most commonly used by the public and tourists will be displayed by abbreviations. For example, For example, $F \& B$ 餐饮服务. 5) The conjunction of words and symbols: public signs are often used in conjunction with striking signs. They are easy to understand and complement each other. And those signs usually use present tense. Public signs are given to the public in a specific area by means of instructions, prompting and restrictions of real behaviors. Therefore, the tense application is limited to the present time. Such as, Don't Drive When Tired 严禁疲劳驾驶. 6) The amount of imperative sentences: public signs involve amount of imperative sentences, as the public is in a hurry to go out or travel, the public signs are clear for the target public. Imperative sentences are more euphemism and are easy for foreign guests to accept. Therefore, public signs are applied to imperative sentences widely. For example Do Not Disturb 请勿打扰. 7) The strict standardization of vocabulary: due to the importance of public signs in public and tourist life, any ambiguity or misunderstanding can lead to adverse consequences. English public signs related to daily life are norms and standards expressed in practice for many years, and express vocabularies. For example, Two Way双向行使, Ramp Speed 斜坡限速. 8)The concise of language option: the English public signs are simple and precise. As long as they do not affect the specific functions and meanings of the public signs, only the words, key words, and the core words are used, and the articles, pronouns, and auxiliary words can be omitted. For Example, Locker Room 更衣室.

\section{Analysis of public signs and its translation strategies}

Whether the translation of the public signs can meet the requirements of the audience is suitable for the specific communicative context, and whether it can achieve the desired function in the cultural environment of the human language, to a great extent, depends on whether the translation can be understood, and accepted by the target audience ${ }^{[3]}$. According to pragmatic analysis of public signs what said above, there are some translation strategies for public signs, that are identification of context, appropriate choice of words, consideration of cultural differences.

\subsection{Identification of context}

The concept of context is proposed functional linguist Malinowski in 1923, Malinowski in the concept, is actually from the perspective of the translator's perspective. In translation practice, he realized the importance of situational context and the restrictive effect of situational context on translation ${ }^{[10]}$. He believes that even after translation, the original text cannot be fully understood by people living outside the original context, because each message conveys more meaning than the speech itself, and only by understanding the original context at the same time, the meaning can be understood more fully. That is to say, the understanding and translation of the original text can only be achieved in a specific context. All the factors including diction, syntactic structure and style, all cannot take effect without the specific context. Therefore, context constitutes the basis for accurate translation. Take “注意安全” for example, it is often translated as Pay Attention to Safety or Notice Safety when working or active in a charged region, it can be translated into "Danger! Electric Shock! /Danger! Voltage".

\subsection{Appropriate choice of words}

There are many synonyms in English, which are easy to confuse and also lead to all kinds of translation which leave an embarrassing situation for people. Translation of English and Chinese words should avoid mechanical equivalence, should pay 
attention to the effect of expression ${ }^{[8]}$. For Example, “特产” is translated into Special Products of, however, it's better to translate it into specialties. “小心碰头” in some public place is translated into pay attention to your head ,but here “小心”should be translated into mind. That is one more example, “Toll Gate”(收费站) usually refers to high express highway or bridge toll office, but many parks sales offices use this phrase directly.

\subsection{Consideration of cultural differences}

Any language is a product of specific social culture and rooted in specific cultural background. Different cultures have different ways of expressing their thinking. When translating public signs, we should change our mindset and take cultural differences into consideration, make public signs conform to the English expressions ${ }^{[1]}$. Hospitals in China have public signs goes like that “文明 行医，文明就医”， but its corresponding translation is “Civilized Practice, Civilized Hospitalization”. If foreigners look at such signs, they will think that hospitals in China are advocating civilized practice, then there must be uncivilized practice. However, in the same context, the hospitals in Hongkong area expressed it in a different way that is "Sharing and Caring". Although this sentence is divorced from the original word, it reads catchy, and gained wide cultural identity among westerners.

\section{Conclusion}

Public signs are "business cards" for a country or city to publicize. Public signs reflect the degree of internationalization and cultural connotations of a city. When translating public signs, we should try to use English public signs with the same context and pragmatic equivalently in English countries, so as to achieve the purpose of communication. Due to the limitation of time and space, public signs are inappropriate to use long sentences. When translated public signs we should make sentences simple and clear as much as possible, we should adhere to the principle of politeness, use mild euphemism and praise words to avoid emotional conflict, pay attention to the principle of cooperation and the information of public display, to reach the audience's combined information, more important use the context correctly. The diagram is clear and the pragmatic strategy is appropriate. Only in this way can we fully realize the pragmatic functions of public signs and make the public feel more comfort.

\section{References}

1. He Ziran. An Introduction to Pragmatics[M].Hunan Education Press, 1988.

2. Li Jinxia. The Cooperative Principle and Politeness Principle in The Analects of Confucius[J]. Social Science Journal, 2007 (3).

3. J. J. McGraw, Translation and Translation[M].Cambridge: Cambridge University Press, 1989.

4. J. J. McGraw, Pragmatics and Pragmatics[M].New York: Cambridge University Press, 2000.

5. G rice, H.P. Logic and Conversation[M].New York Academic Press, 1975.

6. Leach, G.N. Principles of Pragmatics[M].London: Long — man Group Limited, 1983.

7. Austin, J.L. How to Do Things with Words[M].Oxford University Press 1962.

8. Thomas J. Cross - cultural Pragmatic Failure[J].Applied Linguistics, 1984 (4 ).

9. Niu Xinsheng. The Types and Translation of Published Texts. Foreign Language Teaching, 2008 (3): 89-93.

10. Zhang Meifang. Translation Studies in China, 2009 (5): 53-60 (in Chinese): A Typological Approach to the Study of Public Signs and Their Implications for Translation Studies. 